\title{
RANCANG BANGUN APLIKASI E-LIBRARY FAKULTAS TEKNIK UNIVERSITAS MUHAMMADIYAH TANGERANG
}

\author{
Syepry Maulana Husain ${ }^{1)}$, Lukman Azhari' ${ }^{2)}$, Rohmat Taufiq ${ }^{3)}$, Atika Rahma ${ }^{4}$ \\ 1,2,3 Program Studi Teknik Informatika, Fakultas Teknik Universitas Muhammadiyah Tangerang \\ Email: shevrie18@gmail.com,lukmanazhari85@gmail.com,rohmat.taufiq@gmail.com, \\ atikarahma339@gmail.com
}

\begin{abstract}
Article history

Received Oct 2,

2020

Revised Okt 30

2020

Accepted Nov 30,

2020

Available online Nov 30, 2020

Keywords

Library, e-Library

application,

Android, RAD.

The Faculty of Engineering e-Library application is an application that is used to help the Library section manage data and transactions at the Engineering Faculty Library, Muhammadiyah University of Tangerang. This application is used by officers to make it easier to record borrowing and returning books in monitoring available and borrowed books. This application was created using the Software Development Life Cycle (SDLC) system development method with the Rapid Application Development (RAD) model. The development of this application is in the form of an Android application that can be accessed by library members and connected to the Website application that is accessed by librarians. The Angroid application is built using the PHP programming language with the Codeigniter Framework and the Android application using the Dart programming language with the Flutter Framework. Whereas in the system testing method using blackbox testing.
\end{abstract}

Keywords: Library, e-Library application, Android, RAD.

\section{Abstrak}

Riwayat

Diterima 2 Okt 2020

Revisi 30 okt, 2020

Disetujui $30 \mathrm{Nov}$ 2020

Terbit 30 Nov 2020

Kata Kunci Perpustakaan, Aplikasi eLibrary, Android, RAD

Aplikasi e-Library Fakultas Teknik adalah sebuah aplikasi yang digunakan untuk membantu bagian Perpustakaan melakukan pengelolaan data dan transaksi pada Perpustakaan Fakultas Teknik Universitas Muhammadiyah Tangerang. Aplikasi ini digunakan oleh petugas agar lebih mudah dalam melakukan pencatatan peminjaman dan pengembalian buku dalam memantau buku yang tersedia dan dipinjam. Aplikasi ini dibuat dengan menggunakan metode pengembangan sistem Software Development Life Cycle (SDLC) dengan model Rapid Application Development (RAD). Pembangunan aplikasi ini berupa aplikasi Android yang dapat diakses oleh anggota perpustakaan dan terhubung dengan aplikasi Website yang diakses oleh petugas perpustakaan. Aplikasi angroid dibangun menggunakan Bahasa pemrograman PHP dengan Framework Codeigniter dan aplikasi Android menggunakan Bahasa pemrograman Dart dengan Framework Flutter. Sedangkan dalam metode pengujian sistem menggunakan pengujian blackbox testing.

Kata kunci: Perpustakaan, Aplikasi e-Library, Android, RAD

\section{PENDAHULUAN}

Universitas Muhammadiyah Tangerang merupakan perguruan tinggi swasta yang didirikan sejak tahun 2009 dan merupakan PTM terbesar dengan jumlah mahasiswa terbanyak di Provinsi Banten, selain itu Universitas Muhammadiyah Tangerang juga memiliki beberapa Fakultas, salah satunya yaitu Fakultas Teknik. 
Pada Fakultas Teknik Universitas Muhammadiyah Tangerang terdapat 5 (lima) program studi, yaitu Teknik Elektro, Teknik Sipil, Teknik Informatika, Teknik Industri dan Teknik Mesin. Kurikulum Fakultas Teknik dirancang berbasis manufaktur dan jasa yang disesuaikan dengan teknologi yang terus berkembang dan mempengaruhi perilaku manusia di dunia usaha dan dunia industri, maka untuk memenuhi akreditasi pada Fakultas Teknik dibangun sebuah Perpustakaan sebagai tempat atau sarana untuk menunjang pembelajaran bagi mahasiswa Fakultas Teknik.

Perpustakaan merupakan tempat yang bisa dimanfaatkan untuk mencari beberapa sumber informasi dan referensi buku untuk dipinjam dan dibaca ditempat. Perpustakaan membutuhkan pengelolaan yang baik dan professional terhadap koleksi-koleksi yang ada di perpustakaan. Namun, pada Perpustakaan Fakultas Teknik masih memiliki berbagai hambatan sehingga belum bisa berjalan sebagaimana mestinya. Seperti kurangnya informasi dalam ketersediaan koleksi buku yang ada dan informasi mengenai jam operasional perpustakaan yang kurang maksimal, sehingga mahasiswa atau anggota kesulitan saat akan mengunjungi perpustakaan untuk meminjam atau hanya sekedar membaca buku di perpustakaan. Oleh sebab itu, diperlukan sebuah perangkat yang dapat memberikan informasi buku perpustakaan dan proses peminjaman buku yang dapat diakses secara mobile yang dilakukan dengan menggunakan smartphone.

Perangkat smartphone memiliki banyak fungsi seperti berkomunikasi melalui pesan singkat, menyimpan file, atau bahkan untuk sekedar mencari informasi dari internet menggunakan smartphone, dan sistem operasi yang paling banyak digunakan adalah Android. Maka diperlukan sebuah sistem yang dapat menangani masalah tersebut, yaitu aplikasi berbasis android untuk Perpustakaan.

Berdasarkan ulasan diatas, agar terbentuknya sistem yang dapat membantu proses pengelolaan data perpustakaan, maka akan diajukan penelitian tugas akhir dengan menetapkan judul "Rancang Bangun Aplikasi e-Library Fakultas Teknik Universitas Muhammadiyah Tangerang Berbasis Android".

\section{KAJIAN LITERATUR}

a. Perancangan

Menurut Munawar (2018),

Perancangan adalah bagaimana sistem akan dibangun meski mungkin faktanya tidak benar-benar diwujudkan. Model yang dibuat pada fase perancangan harus menunjukkan bagaimana berbagai bagian akan bekerja bersama.

b. Aplikasi

Menurut Pramana (2010), Aplikasi adalah suatu unit perangkat lunak yang dibuat untuk melayani kebutuhan akan beberapa aktivitas seperti sistem perniagaan, game pelayanan masyarakat, periklanan, atau semua proses yang hampir dilakukan manusia.

\section{c. Perpustakaan}

Menurut Basuki (2014), Perpustakaan merupakan sarana yang teramat vital dalam proses belajar mengajar, oleh karena itu perpustakaan sering dipandang sebagai jantung program pendidikan (the heart educational program). Dalam bidang perpustakaan mereka memberikan berbagai macam pendapat tentang pengertian perpustaakan.

\section{METODE PENELITIAN}

Jenis penelitian yang digunakan dalam proses penulisan ini adalah Studi Kasus (Case Study Research) yang merupakan serangkaian kegiatan ilmiah yang dilakukan secara intensif, terinci, dan mendalam tentang suatu program, peristiwa, dan aktivitas, baik pada tingkat perorangan, sekelompok orang, lembaga, atau organisasi untuk memperoleh pengetahuan mendalam tentang peristiwa tersebut dalam jangka waktu tertentu dan mengumpulkan data dari berbagai sumber (observasi, dokumen, laporan, atau wawancara).

Metode pengembangan sistem yang digunakan adalah Software Development Life Cycle (SDLC) dengan model Rapid Application Development (RAD) yang 
dimana tahapan-tahapan tersebut adalah sebagai berikut:
a. Pemodelan Bisnis (Bussiness Modeling)
b. Pemodelan Data (Data Modeling)
c. Pemodelan Proses (Process Modelling)
d. Pembentukan Aplikasi (Aplication Generation)
e. Pengujian dan Pergantian (Testing and Turnover)

\section{HASIL DAN PEMBAHASAN}

\section{A. Analisa Sistem Berjalan}

1) Anggota perpustakaan harus datang langsung ke perpustakaan, untuk dapat meminjam buku atau hanya sekedar membaca buku diperpustakaan.

2) Setiap mahasiswa Universitas Muhammadiyah Tangerang yang aktif adalah anggota Perpustakaan Fakultas Teknik, sehingga tidak adanya batasan bahwa hanya mahasiswa Teknik saja yang dapat meminjam buku di Perpustakaan Fakultas Teknik.

3) Dalam proses peminjaman buku perpustakaan tidak terdapat batas berapa banyak jumlah buku yang dapat dipinjam oleh anggota perpustakaan.

4) Kurangnya informasi dalam batas pengembalian buku dan nominal denda yang dihitung perharinya sesuai waktu keterlambatan menyebabkan banyaknya anggota perpustakaan yang lalai bahkan lupa kapan batas buku tersebut dikembalikan, sehingga buku yang dipinjam dapat hilang ataupun rusak.

5) Laporan yang dihasilkan rentan terjadi kesalahan karena untuk dapat mengetahui laporan informasi data buku untuk daftar inventaris buku atau buku induk perpustakaan yang dihasilkan tidak ada informasi jumlah laporan pengunjung dengan grafik perhari, perbulan dan bertahun.

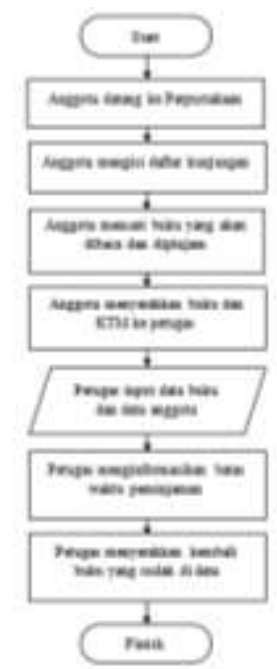

Gambar 4.1 Prosedur Sistem Berjalan (1)

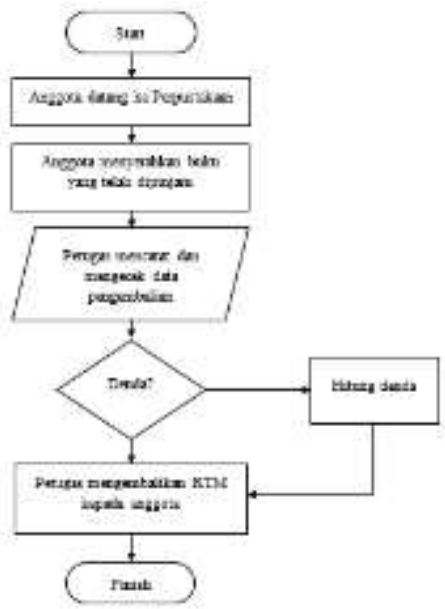

Gambar 4.2 Prosedur Sistem Berjalan (2)

\section{Pengembangan Sistem}

1) Pemodelan Bisnis (Bussiness Modeling)

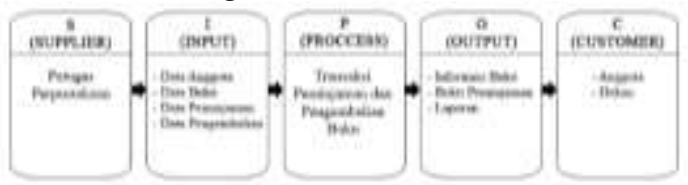

Gambar 4.3 Diagram SIPOC

2) Pemodelan Data (Data Modeling)

\section{B. Prosedur Sistem Berjalan}



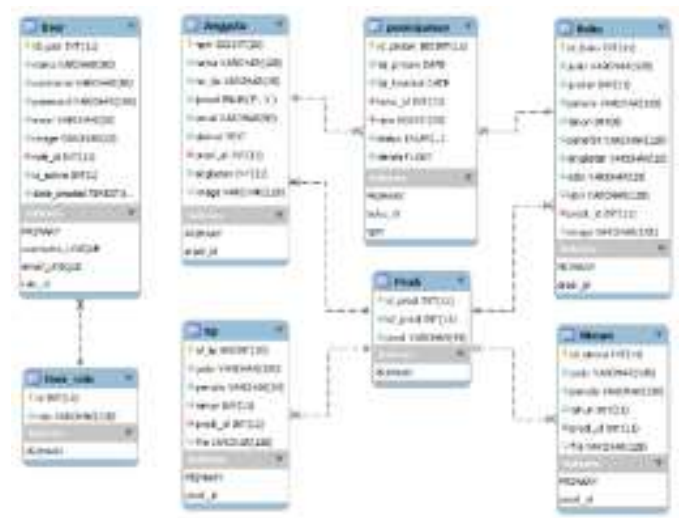

Gambar 4.5 Diagram ERD (Entity Relationship Diagram)

3) Pemodelan Proses (Process Modelling)

a. Usecase Diagram Admin

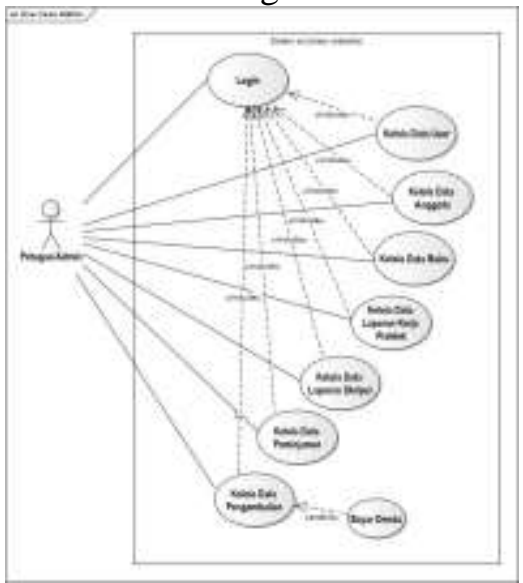

Gambar 4.6 Use case diagram admin

b. Usecase Diagram Anggota

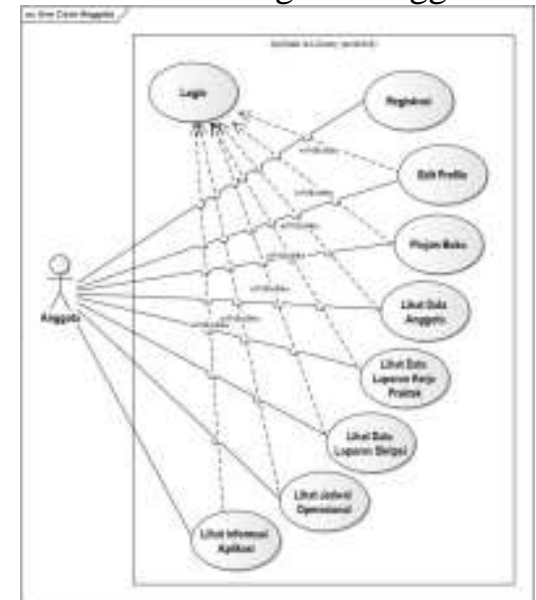

Gambar 4.7 Use case diagram anggota

\section{c. Actifity Diagram}

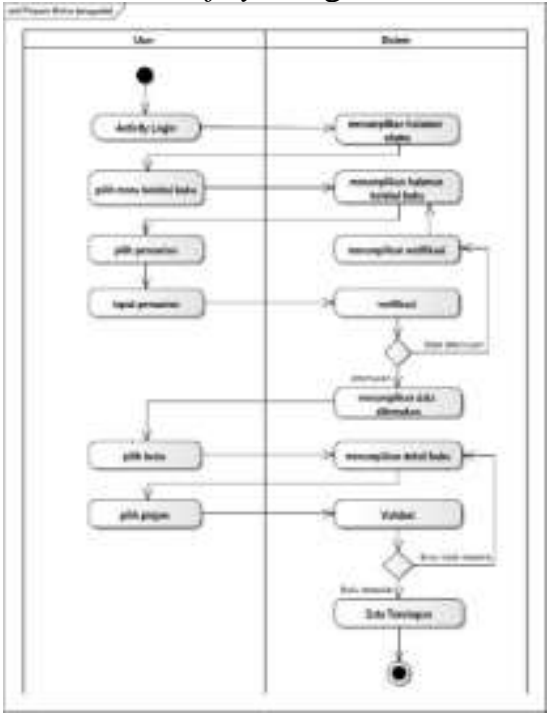

Gambar 4.8 Activity diagram pinjam buku (anggota)

d. Sequence Diagram

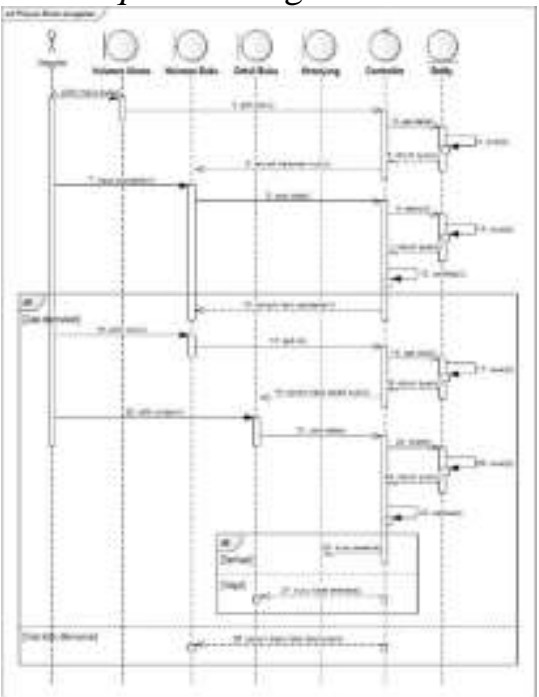

Gambar 4.9 Sequence diagram pinjam buku (anggota)

e. Class Diagram 


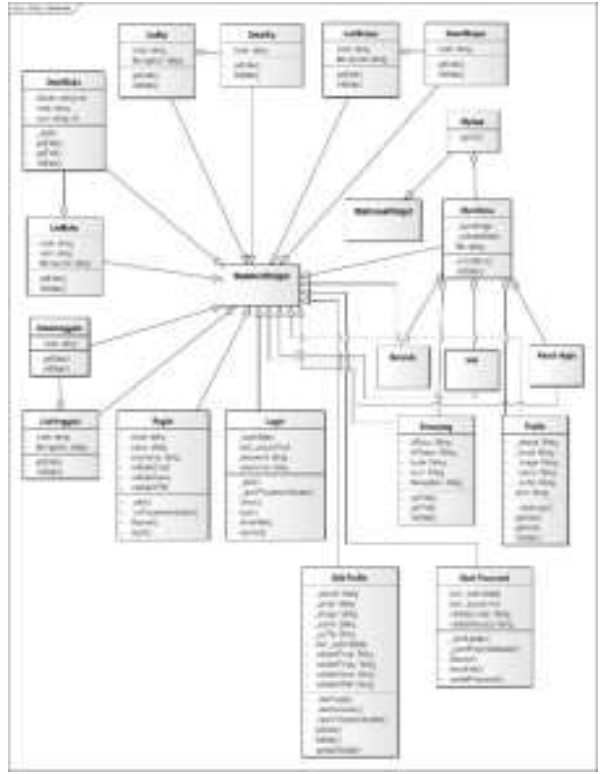

Gambar 4.10 Class diagram

4) Pembentukan Aplikasi (Aplication Generation)

a. Halaman login

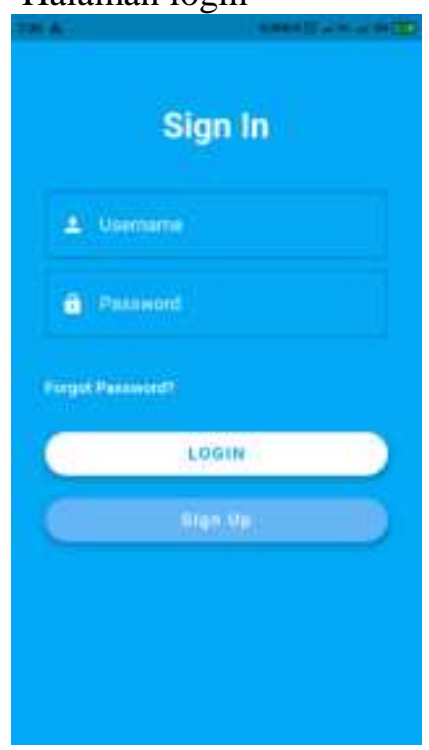

Gambar 4.11 User interface halaman login b. Halaman utama

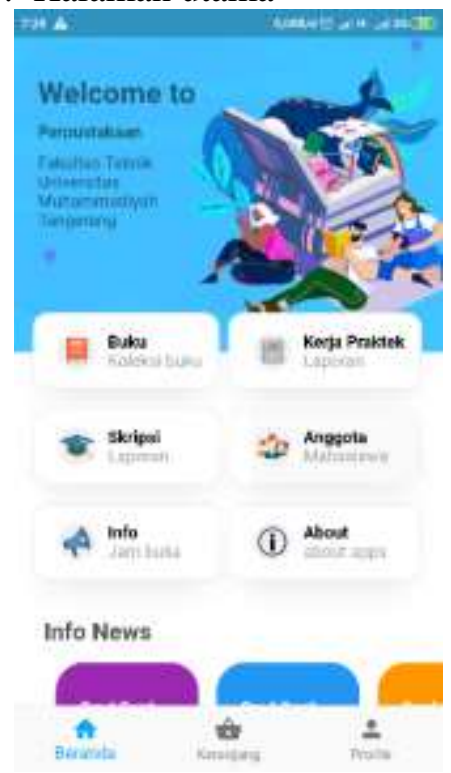

Gambar 4.12 User interface halaman utama

c. Halaman buku

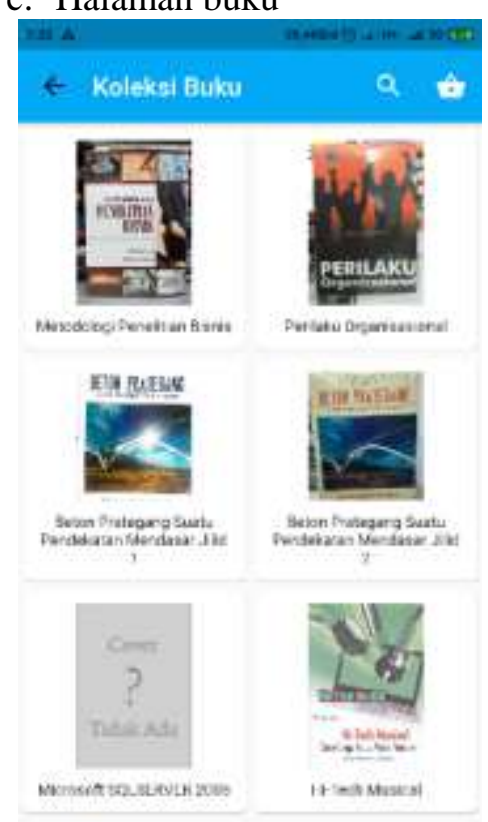

Gambar 4.13 User interface halaman buku

d. Halaman pinjam buku 


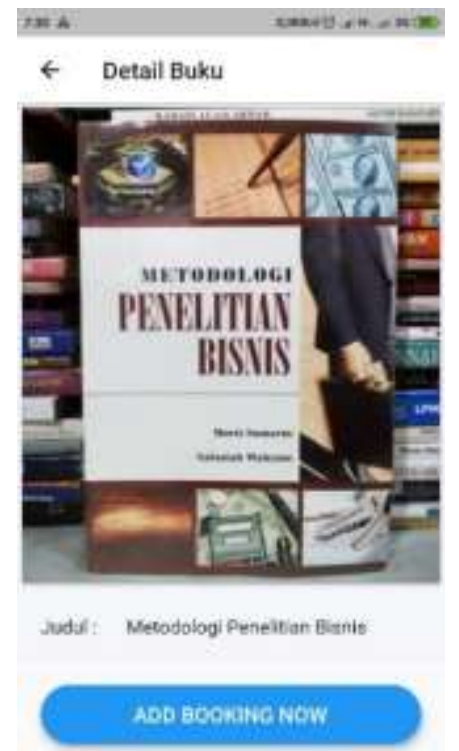

Gambar 4.14 User interface halaman pinjam buku

e. Halaman edit profile

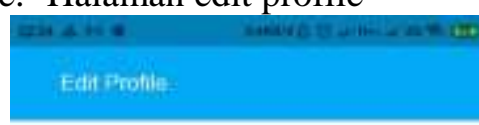

1655201279

Atika Rahme

Atika Rathro

atikarahme339@ggmalcom

mi tamplem whatupe

089694239362

Galarajo, Kab.Tangerang

SUMPAN

Gambar 4.15 User interface halaman edit profile

5) Pengujian dan Pergantian (Testing and Turnover)

Tabel 4.1 Black Box Login

\begin{tabular}{|c|c|c|c|c|}
\hline $\mathrm{N}$ & Peng & $\begin{array}{c}\text { Hasil } \\
\text { yang di }\end{array}$ & $\begin{array}{c}\text { Hasil } \\
\text { ujian }\end{array}$ & $\begin{array}{c}\text { Kesim } \\
\text { pulan }\end{array}$ \\
\hline
\end{tabular}

\begin{tabular}{|c|c|c|c|c|}
\hline 1 & $\begin{array}{l}\text { Logi } \\
\mathrm{n} \\
\text { Apli } \\
\text { kasi }\end{array}$ & $\begin{array}{l}\text { Aplikasi } \\
\text { akan } \\
\text { menampil } \\
\text { kan form } \\
\text { Login }\end{array}$ & \begin{tabular}{l} 
Menampilk \\
an form \\
input \\
username \\
dan \\
password \\
\multicolumn{1}{c}{} \\
\end{tabular} & Valid \\
\hline 2 & $\begin{array}{l}\text { User } \\
\text { nam } \\
\mathrm{e} \\
\text { dan } \\
\text { pass } \\
\text { word } \\
\text { koso } \\
\text { ng }\end{array}$ & $\begin{array}{l}\text { Aplikasi } \\
\text { akan } \\
\text { menampil } \\
\text { kan } \\
\text { kesalahan } \\
\text { pada field } \\
\text { username } \\
\text { dan } \\
\text { password } \\
\text { dan gagal } \\
\text { login }\end{array}$ & \begin{tabular}{|l} 
Menampilk \\
an \\
kesalahan \\
pada field \\
input dan \\
gagal login \\
\end{tabular} & Valid \\
\hline 3 & $\begin{array}{l}\text { User } \\
\text { nam } \\
\mathrm{e} \\
\text { bena } \\
\text { r dan } \\
\text { pass } \\
\text { word } \\
\text { salah }\end{array}$ & $\begin{array}{l}\text { Aplikasi } \\
\text { akan } \\
\text { menampil } \\
\text { kan pesan } \\
\text { kesalahan } \\
\text { dan gagal } \\
\text { login }\end{array}$ & $\begin{array}{l}\text { Menampilk } \\
\text { an pesan } \\
\text { kesalahan } \\
\text { pada form } \\
\text { login }\end{array}$ & Valid \\
\hline 4 & $\begin{array}{l}\text { User } \\
\text { nam } \\
\mathrm{e} \\
\text { dan } \\
\text { pass } \\
\text { word } \\
\text { bena } \\
\mathrm{r}\end{array}$ & $\begin{array}{l}\text { Aplikasi } \\
\text { akan } \\
\text { menampil } \\
\text { kan menu } \\
\text { utama } \\
\text { dan } \\
\text { berhasil } \\
\text { login }\end{array}$ & $\begin{array}{l}\text { Menampilk } \\
\text { an menu } \\
\text { utama }\end{array}$ & Valid \\
\hline
\end{tabular}

Tabel 4.2 Black Box halaman pinjam buku 


\begin{tabular}{|c|c|c|c|c|}
\hline $\begin{array}{l}\mathrm{N} \\
\mathrm{O}\end{array}$ & $\begin{array}{c}\text { Pengu } \\
\text { jian }\end{array}$ & $\begin{array}{c}\text { Hasil } \\
\text { yang di } \\
\text { Harapkan }\end{array}$ & $\begin{array}{c}\text { Hasil } \\
\text { Pengujian }\end{array}$ & $\begin{array}{c}\text { Kesi } \\
\text { mpul } \\
\text { an }\end{array}$ \\
\hline 1 & $\begin{array}{l}\text { Menu } \\
\text { Kolek } \\
\text { si } \\
\text { Buku }\end{array}$ & $\begin{array}{l}\text { Aplikasi } \\
\text { akan } \\
\text { menampil } \\
\text { kan } \\
\text { halaman } \\
\text { koleksi } \\
\text { buku }\end{array}$ & $\begin{array}{l}\text { Menampilk } \\
\text { an halaman } \\
\text { koleksi } \\
\text { buku }\end{array}$ & Valid \\
\hline 2 & $\begin{array}{l}\text { Pilih } \\
\text { Buku }\end{array}$ & $\begin{array}{l}\text { Aplikasi } \\
\text { akan } \\
\text { menampil } \\
\text { kan detail } \\
\text { data buku }\end{array}$ & $\begin{array}{l}\text { Menampilk } \\
\text { an detail } \\
\text { data buku } \\
\text { dan button } \\
\text { pinjam }\end{array}$ & Valid \\
\hline 3 & $\begin{array}{l}\text { Butto } \\
n \\
\text { Pinja } \\
\mathrm{m}\end{array}$ & $\begin{array}{l}\text { Aplikasi } \\
\text { akan } \\
\text { menampil } \\
\text { kan data } \\
\text { buku di } \\
\text { halaman } \\
\text { keranjang }\end{array}$ & $\begin{array}{l}\text { Menampilk } \\
\text { an data } \\
\text { buku di } \\
\text { halaman } \\
\text { keranjang }\end{array}$ & Valid \\
\hline
\end{tabular}

\section{KESIMPULAN DAN SARAN}

\section{A. Kesimpulan}

1) Sistem pengolahan data yang berjalan pada Perpustakaan Fakultas Teknik menggunakan Microsoft Office Excel.

2) Proses pembuatan aplikasi e-Library pada Fakultas Teknik menerapkan metode pengembangan sistem Software Development Life Cycle (SDLC) dengan model Rapid
Application Development (RAD), yang terdiri dari beberapa tahapan yaitu pemodelan bisnis, pemodelan data, pemodelan proses, pembentukan aplikasi, hingga pengujian dan testing.

3) Aplikasi yang dibangun mampu memfasilitasi petugas untuk mengelola pendataan buku, anggota, transaksi peminjaman dan pengembalian buku secara terkomputerisasi dengan aplikasi melalui web. Anggota juga dapat dengan mudah mencari informasiinformasi mengenai Perpustakaan melalui Aplikasi Android. Dengan aplikasi yang diusulkan, pengguna dapat dengan mudah mencari informasi-informasi mengenai Perpustakaan Fakultas Teknik Universitas Muhammadiyah Tangerang.

\section{B. Saran}

1) Perlu dilakukan pengembangan terhadap sistem sehingga sistem yang ada dapat dimanfaatkan secara lebih optimal.

2) Perlu ditambahkan fitur-fitur tambahan seperti cetak bukti peminjaman dan notifikasi tenggat waktu pengembalian buku pada aplikasi Android.

3) Penerapan pengolahan data yang berbasis komputer sebaiknya tidak langsung menggantikan sistem lama tetapi berjalan secara bertahap, tujuannya agar dapat melakukan perbandingan antara hasil sistem yang lama dengan sistem yang baru. Karena bagaimanapun juga sistem ini masih terdapat kekurangan dan hanya sebagai alat yang apabila tanpa ada manusia yang bisa mengendalikannya tidak akan bermanfaat bagi yang menggunakannya.

\section{DAFTAR PUSTAKA}

Abdullah, Dahlan. (2017). Merancang Aplikasi Perpustakaan Menggunakan SDLC. Medan: Penerbit Sefa Bumi Persada. 
Apache Friends - Xampp Apache + MariaDB + PHP + Perl - 15 April 2020 - ht https://www.apachefriends.org/index.ht $\underline{\mathrm{ml}}$

Arianto M.A, Munir Sirojul, Khotimah K. (2016). Analisis Dan Perancangan Representational State Tranfer (REST) Web Service Sistem Informasi Akademik STT Terpadu Nurul Fikri Menggunakan YII Framework. Jurnal Teknologi Terpadu Vol. 2, No. 2.

Bachtiar, Adam M. \& Fakhrul, Firman N. (2018). Pemrograman Berorientasi Objek Menggunakan Java. Bandung: Penerbit Informatika.

Balsamiq Mockups - Senin, 12 Oktober 2020 https://balsamiq.com/wireframes

Basuki, Sulistyo. (2014). Materi Pokok Pengantar Ilmu Perpustakaan. Tangerang Selatan: Penerbit Universitas Tekbuka.

Daqiqil, Ibnu. (2011). Framework CodeIgniter Sebuah Panduan dan Best Practice. eBook Kumpulan Tutorial Komputer.

Giza, Kay \& Kahlert, Tobias. (2016). Visual Studio Code - Tips And Tricks -Vol.1. Jerman: Penerbit Microsoft.

Hakim. S. 2017. Rancang Bangun Dashboard Information System Tracer Alumni Pada Teknik Informatika Universitas Muhammadiyah Tangerang. Skripsi. Universitas Muhammadiyah Tangerang.

Husain, S. M. 2014. Pemanfaatan Basic4android Dan Mysql Dalam Membangun Aplikasi Smartphone Untuk Memonitoring Prestasi Siswa Pada SMA AlMa'muniyah Tangerang. Skripsi. STMIK Raharja.

Juhara, Zamrony P. (2016). Panduan Lengkap Pemrograman ANDROID. Yogyakarta: CV. ANDI.

Jugiyanto, HM. (2014). Analisis dan desain sistem informasi : pendekatan terstruktur teori dan praktik aplikasi bisnis Edisi III. Yogyakarta.

Kurniawan, Syahrizal. 2017. Rancang Bangun Sistem Informasi Portal Alumni Berbasis Web Pada Smk Perintis 1 Sepatan Kabupaten Tangerang. Skripsi.
Universitas Muhammadiyah Tangerang.

Munawar, (2018). Analisis Perancangan Sistem Berorientasi Objek dengan UML. Bandung : Penerbit Informatika.

Mustakini, Jogiyanto Hartono. (2009). Sistem Teknologi Informasi. Yogyakarta: Penerbit Andi.

Mulyanto, Agus. (2009). Sistem Informasi Konsep \& Aplikasi. Yogyakarta: Pustaka Pelajar.

MySQL Workbench - Senin, 12 Oktober 2020 https://www.mysql.com/products/work bench/

Nurnaningsih, Desy, Rachmat Destriana, and Djamaludin Syahlan Mubaroq. "RANCANG BANGUN SISTEM INFORMASI PENGARSIPAN SURAT MASUK DAN KELUAR STUDI KASUS PADA CV SUMBER KARYA TEKNIK." JIKA (Jurnal Informatika) 3.2 (2019).

Pramana, H. W. 2012. Aplikasi Inventory Berbasis Access 2003. Jakarta: PT. Elex Media Komputindo.

Purnomo, Dwi. (2017). Model Prototyping Pada Pengembangan Sistem Informasi Vol.2. Malang: Jurnal Informatika Merdeka Pasuruan.

Riman, Muhammad Rifki, 2014. Rancang Bangun Sistem Informasi Akademik Berbasis Web pada Sekolah Dasar Negeri Kebayoran Lama Utara 13 Pagi Jakarta Selatan, Skripsi, Universitas Islam Negeri Syarif Hidayatullah Jakarta.

Rinaldi, Reno, 2018. Rancang Bangun Sistem Informasi Perpustakaan Berbasis Web pada SMP Muhammadiyah 4 Tangerang, Skripsi, Universitas Muhammadiyah Tangerang.

Rizky, S. 2011. Konsep Dasar Rekayasa Perangkat Lunak. Jakarta: Prestasi Pustaka.

Rosa, A.S., \& M. Shalahuddin. (2018). Rekayasa Perangkat Lunak Terstruktur dan Berorientasi Objek Edisi Revisi. Bandung: Penerbit Informatika

Sharma, Neeraj. (2010). Database Fundamentals Ideal for Application Developers and Administrators. Canada: IBM Corporation. 
Simarmata, Janner. (2010). Perancangan Basis Data. Yogyakarta: CV. Andi Ofsset.

Sparx System - Enterprise Architect - Rabu, 10 April 2020

https://sparxsystems.com.au/enterprisearchitect/

Sumasno, Indra, 2019. Aplikasi E-Commerce Sistem Informasi Penjualan Rolling Door Berbasis RAD (Rapid Application Development), Skripsi, Universitas Raharja - Rabu, 1 Juli 2020 http://widuri.raharja.info/index.php?titl e=SI1322476247\#Elisitasi

Suwandi, Six Sigma Indonesia - SIPOC Analisys - Senin, 8 Juni 2020 http://sixsigmaindonesia.com/sipocanalysis/

Syaputra, Rizki \& Wiraganda, Yusmi P. (2019). Happy Flutter - Membuat Aplikasi Android dan iOS dengan Mudah
Menggunakan Flutter. Jakarta: Penerbit Udacoding

Venna, Farah C. 2019. Implementasi Steganografi Audio pada File Wav dengan Metode Redudant Pattern Ancoding (RPE) Berbasis Android. Skripsi. UIN Syarif Hidayatullah Jakarta

Widuri Raharja, Elisitasi - Rabu, 22 Juli 2020 https://widuri.raharja.info/index.php?tit le=Elisitasi

Yakub. (2012). Pengantar Sistem Informasi. Yogyakarta: Graha Ilmu.

Yahya. V. 2019. Rancang Bangun Aplikasi Pusat Iinformasi Sekolah dengan Penerapan chatbot menggunakan AIML berbasis Android pada SMK Otomtif Al Husna Tangerang. Skripsi. Universitas Muhammadiyah Tangerang. 